RESEARCH

\section{SERIES}

NUMBER 132

January 2022

\section{HETEROGENEOUS EFFECTS OF A MINIMUM WAGE INCREASE ON HOURS WORKED}

PAUL REDMOND AND SEAMUS MCGUINNESS

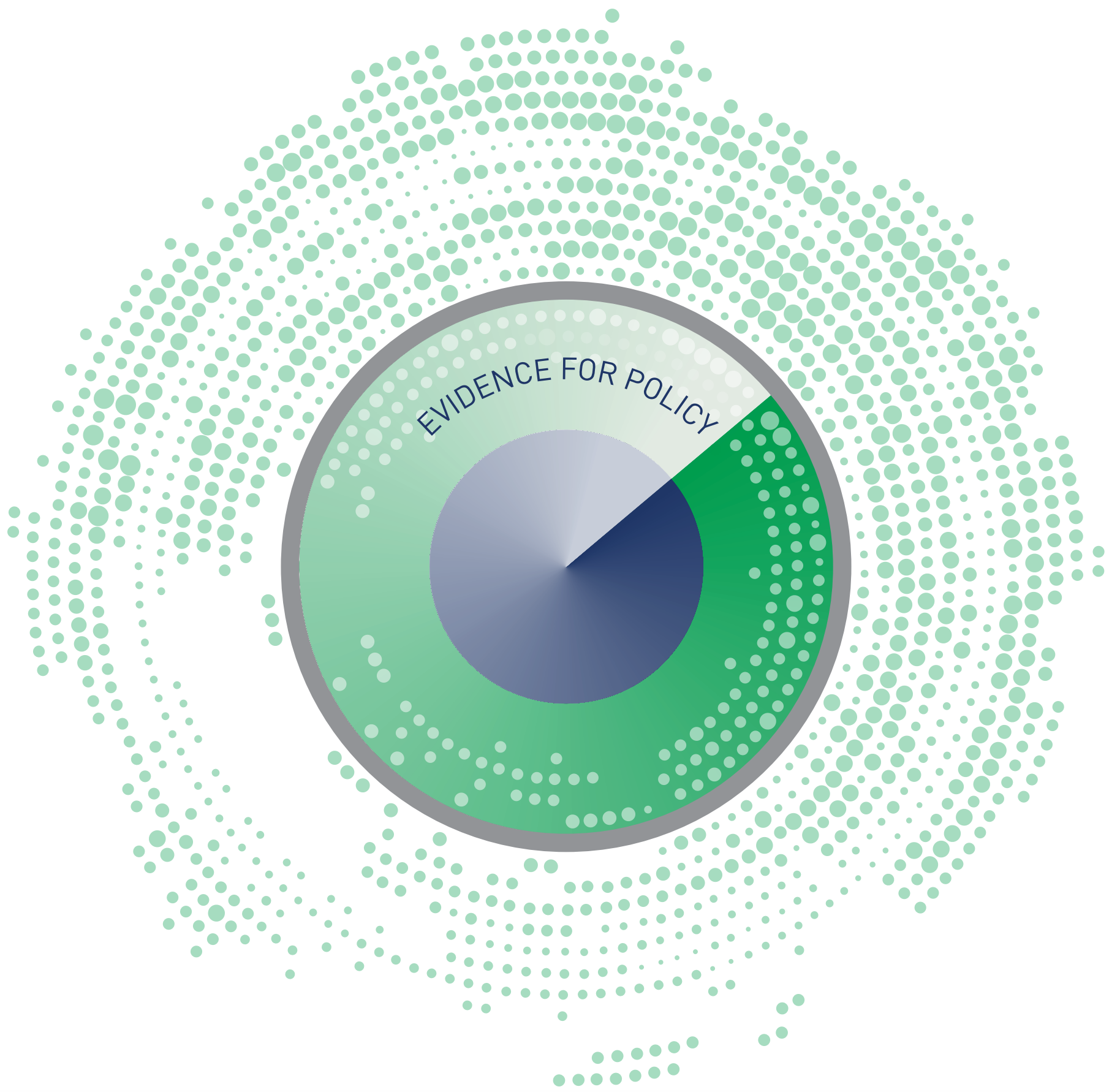




\title{
HETEROGENEOUS EFFECTS OF A MINIMUM WAGE INCREASE ON HOURS WORKED
}

\author{
Paul Redmond \\ Seamus McGuinness
}

January 2022

\section{RESEARCH SERIES}

\section{NUMBER 132}

Available to download from www.esri.ie

The Economic and Social Research Institute

Whitaker Square, Sir John Rogerson's Quay, Dublin 2

https://doi.org/10.26504/rs132

\section{(c) (†)}

This Open Access work is licensed under a Creative Commons Attribution 4.0 International License (https://creativecommons.org/licenses/by/4.0/), which permits unrestricted use, distribution, and reproduction in any medium, provided the original work is properly credited. 



\section{ABOUT THE ESRI}

The mission of the Economic and Social Research Institute is to advance evidencebased policymaking that supports economic sustainability and social progress in Ireland. ESRI researchers apply the highest standards of academic excellence to challenges facing policymakers, focusing on 12 areas of critical importance to 21st Century Ireland.

The Institute was founded in 1960 by a group of senior civil servants led by Dr T. K. Whitaker, who identified the need for independent and in-depth research analysis to provide a robust evidence base for policymaking in Ireland.

Since then, the Institute has remained committed to independent research and its work is free of any expressed ideology or political position. The Institute publishes all research reaching the appropriate academic standard, irrespective of its findings or who funds the research.

The quality of its research output is guaranteed by a rigorous peer review process. ESRI researchers are experts in their fields and are committed to producing work that meets the highest academic standards and practices.

The work of the Institute is disseminated widely in books, journal articles and reports. ESRI publications are available to download, free of charge, from its website. Additionally, ESRI staff communicate research findings at regular conferences and seminars.

The ESRI is a company limited by guarantee, answerable to its members and governed by a Council, comprising 14 members who represent a cross-section of ESRI members from academia, civil services, state agencies, businesses and civil society. The Institute receives an annual grant-in-aid from the Department of Public Expenditure and Reform to support the scientific and public interest elements of the Institute's activities; the grant accounted for an average of 30 per cent of the Institute's income over the lifetime of the last Research Strategy. The remaining funding comes from research programmes supported by government departments and agencies, public bodies and competitive research programmes.

Further information is available at www.esri.ie 


\section{THE AUTHORS}

Paul Redmond is a Research Officer at the ESRI and an Adjunct Assistant Professor at Trinity College Dublin. Seamus McGuinness is a Research Professor at the Economic and Social Research Institute (ESRI) and an Adjunct Professor at TCD.

\section{ACKNOWLEDGEMENTS}

The work carried out in this report was funded by the Low Pay Commission. We would like to thank all individuals within the Commission who provided assistance during the project and provided us with valuable comments on earlier drafts of the report. We would also like to thank the Central Statistics Office for access to the data used in the study.

This report has been accepted for publication by the Institute, which does not itself take institutional policy positions. All ESRI Research Series reports are peer reviewed prior to publication. The authors are solely responsible for the content and the views expressed. 


\section{TABLE OF CONTENTS}

EXECUTIVE SUMMARY .. V

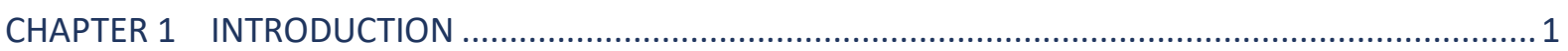

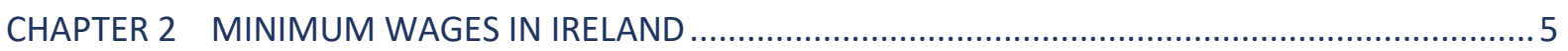

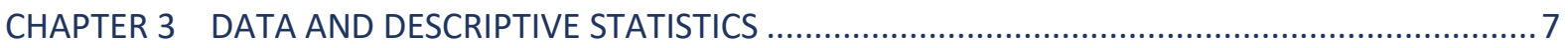

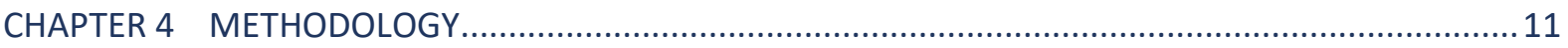

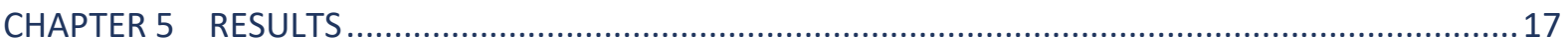

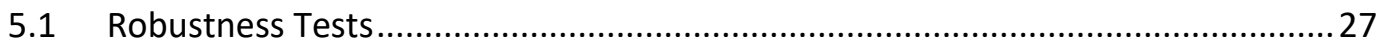

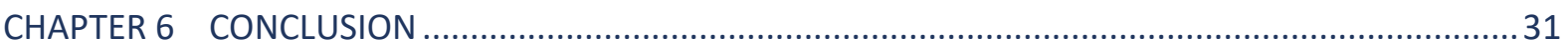

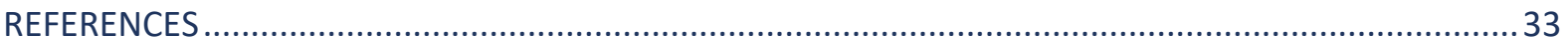




\section{LIST OF TABLES}

Table 3.1 Descriptive statistics of minimum wage and higher paid (non-MW employees).......... 9

Table 5.1 The impact of the 2016 minimum wage increase on hours worked........................... 19

Table 5.2 Difference-in-differences estimates (2016 to 2018) ................................................... 22

Table $5.3 \quad$ Actual 2015 and adjusted 2018 weekly wages..................................................... 27

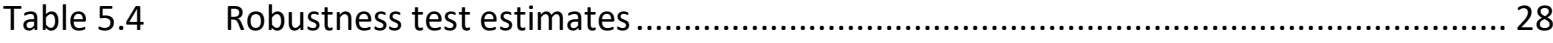

Table 5.5 Robustness test - varying lower threshold of treatment group ................................ 29

Table 5.6 Robustness test - varying upper threshold of control group .................................... 30

\section{LIST OF FIGURES}

Figure 4.1 Illustrative example of fully-flexible difference-in-differences estimator................... 13

Figure 5.1 Average weekly hours worked (2012 to 2018) ....................................................... 17

Figure 5.2 Average weekly hours worked for industry sector employees (2012 to 2018).......... 23

Figure 5.3 Average weekly hours worked for accommodation and food sector employees

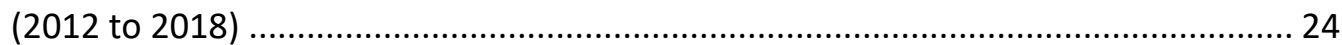

Figure 5.4 Average weekly hours worked for non-national employees (2012 to 2018) ............. 24 


\section{EXECUTIVE SUMMARY}

- This study uses new administrative earnings data, linked to the Irish Labour Force Survey, to analyse the impact of three successive minimum wage increases that took place over the period 2016 to 2018, on the hours worked of minimum wage employees. The study allows for the assessment of the cumulative impact of minimum wage increases that might otherwise be missed in frameworks that examine the yearly policy effect at a particular point in time. This is important as the yearly rate rises from 2016 to 2018 may have a small effect in any one particular year, while amounting to a significant cumulative effect when added together. The data at hand are also sufficient to allow us to test for heterogeneous impacts across different types of minimum wage workers depending on contract type, sector and region.

- Beginning with the impact across all minimum wage employees, while we do not find a statistically significant effect on hours worked in 2016 or 2017 alone, the cumulative effect of the three rate rises over the years 2016, 2017 and 2018 led to a statistically significant reduction of approximately one hour per week in the average number of hours worked by minimum wage employees relative to their slightly higher paid counterparts.

- With respect to heterogeneous impacts, minimum wage workers in the industry sector experienced the largest decline, of approximately three hours per week on average. The employment effects associated with this group may be of particular concern as their characteristics are more indicative of career minimum wage workers, as opposed to younger, part-time workers for which minimum wage employment may be a stepping-stone to higher pay.

- With respect to other heterogeneous impacts, by 2018 minimum wage workers in the accommodation and food sector and non-Irish nationals on the minimum wage were both working 2.5 fewer hours per week. The result for non-Irish nationals reflects the high concentration of such workers in the most affected sectors, namely the accommodation and food sector and the industry sector.

- There was no strong evidence of hours effects within other sectors of the economy, and we did not detect evidence of heterogeneous effects across regions.

- Our analysis indicates that despite the decrease in hours worked, the minimum wage increases from 2016 to 2018 were, on average, high enough to offset the hours decline and therefore raise the weekly wage of minimum wage employees in both nominal and real (inflation adjusted) terms. This was true for minimum wage employees generally, as well as for those in the industry sector and non-Irish nationals on the minimum wage. While minimum wage 
employees in the accommodation and food sector saw a slight increase in nominal wages, in real terms their wages, on average, were unchanged as the hours decline offset the minimum wage increase.

- From a policy perspective, the observed declines in hours worked among minimum wage employees may be a concern, especially among certain groups. Consistent with previous work by McGuinness et al. (2019), we show that minimum wage workers in the industry sector are more likely to resemble 'career minimum wage employees'. Compared to younger, part-time workers who eventually transition to higher paid jobs, career minimum wage employees may be more dependent on their employment to meet financial commitments and may have lower capacity to absorb any decline in weekly earnings. However, while we detect a negative hours effect among minimum wage workers in the industry sector, our analysis indicates that, on average, the minimum wage increases over the period 2016 to 2018 were large enough to offset the hours reductions, thereby leading to an increase in weekly wages in nominal and real terms. 


\section{CHAPTER 1}

\section{Introduction}

The impact of a minimum wage change on employment outcomes has been studied extensively over the last several decades across a wide range of countries and time periods. Despite the accumulated evidence, it remains difficult to definitively state whether a minimum wage increase negatively affects employment outcomes. In recent years, there have been a number of exchanges in academic journals among prominent minimum wage scholars, either challenging or defending papers that find conflicting results, i.e. negative employment effects versus little or no effects (see e.g. Allegretto et al., 2011; 2017; Neumark et al., 2014; Neumark and Wascher, 2017). Several attempts have been made to synthesise the existing evidence to assess what the 'weight of evidence' has to say. One recent example is Dube (2019), who carried out a review of the international evidence on behalf of the UK government. Dube (2019) concludes that the international evidence points to 'muted' effects of minimum wages on employment but cautions that the evidence on high minimum wage rates is still developing, and such policy decisions require careful consideration. In a recent meta-analysis of minimum wage research in the US, Wolfson and Belman (2019) find a small, but statistically significant, negative effect of minimum wages on employment. ${ }^{1}$ However, they note that this finding differs from their metaanalyses published four years earlier (Belman and Wolfson, 2014), as well as the meta-analysis of Doucouliagos and Stanley (2009), both of which did not find statistically significant effects. Therefore, while helpful in assessing the potential impacts of minimum wage increases, meta-analyses, much like individual studies, can arrive at different conclusions.

Motivated by the lack of consensus among minimum wage researchers, Neumark and Shirley (2021) examine what conclusions can be drawn from the minimum wage literature for the US since the early 1990s. Compared to conventional metaanalyses, which often include all estimates from a paper, they directly ask authors of papers about their 'preferred estimate'. This has advantages over including all estimates, as the authors themselves may think some of the estimates are not credible. Neumark and Shirley (2021) find a clear preponderance of negative employment effects in the literature, particularly among studies of directly affected workers. They argue that studies using wage data to accurately capture individuals who will be affected by a minimum wage change are likely to better capture the true effect compared to studies of broad groups of workers (i.e. workers in low-wage industries). The reason is that when broad groups of workers 
are studied, many may be earning above the minimum wage and therefore will not be directly affected by the policy.

A research area that warrants attention, and one that may further explain why employment effects are detected in some studies while not others, is the potential heterogeneous impacts of minimum wage changes on different types of workers. The finding of small, or zero, employment effects when looking at the full population of minimum wage workers could hide the fact that certain types of workers experience negative outcomes. Dickens et al. (2015) find a reduction in employment retention of low-paid, part-time women in the UK. Lordan and Neumark (2018) find substantive adverse employment effects for older, low-skilled manufacturing workers in automatable jobs in the US. Vom Berge and Frings (2020) find regional variation in employment effects associated with the minimum wage in Germany. There is evidence of a negative employment effect in East Germany but no effect in the West, which may be related to a greater minimum wage 'bite' in the East due to lower wages. Other work links heterogeneous employment effects to the type of labour market, indicating that negative employment effects tend not to appear in settings where there is a high degree of monopsony power (Okudaira et al., 2019; Azar et al., 2019).

When discussing employment effects, it is important to note that a binding minimum wage has the potential to impact workers in one of two ways (a) at the extensive margin, whereby there is a reduction in the total number of low paid workers employed, or (b) at the intensive margin, through a reduction in the number of hours worked by low paid employees (Brown 1999). While much of the existing literature focuses on the employment effect measured in terms of the number of jobs (see e.g. Harasztosi and Lindner, 2019; Azar et al., 2019; Stewart, 2004), recent work highlights the importance of the intensive margin (hours worked) as a channel of adjustment. In oral evidence submitted to the UK Low Pay Commission, British retailers indicated that managers look closely at hours adjustments to offset rising labour costs following a minimum wage increase (Metcalf, 2008). There is empirical evidence to support this. Stewart and Swaffield (2008) find that the introduction of the UK minimum wage led to a reduction of between one and two hours per week for low-paid workers. This has also been the focus of several recent studies for Germany, following the introduction of a minimum wage in 2015. In a review of this literature, Caliendo et al. (2019), find broad consensus that the introduction of the German minimum wage was associated with a reduction in hours worked (see Caliendo et al., 2017; Pusch and Rehm, 2017). There is also evidence of an hours reduction related to the minimum wage in the US (Neumark et al., 2004; Couch and Wittenburg, 2001). Therefore, further developing the evidence base on hours worked as an adjustment channel is important in order to fully understand the employment impacts of a minimum wage change. 
In this paper, we focus on hours worked (the intensive margin) as a channel of adjustment. We test for the presence of heterogeneous effects across different types of workers. We use administrative wage data to directly identify affected workers, an approach that Neumark and Shirley (2021) suggest is more suited to capturing minimum wage effects than studying broad groups of workers. Having distinguished workers who are directly impacted by the minimum wage from slightly higher-paid workers, we investigate whether minimum increases led to a reduction in hours worked. We do this for minimum wage workers generally, as well as for minimum wage workers in different sectors, regions, with different contract types (permanent/temporary) and of different nationality (Irish and non-Irish). We are the first to examine such a wide range of potential heterogeneous effects relating to the intensive margin. The Irish data that we use have the advantage of containing several years during which no minimum wage change occurred, followed by several years of minimum wage increases. Using a fully flexible difference-in-differences estimator, we use the pre-treatment years to test for the presence of common pre-treatment dynamics, while using the posttreatment years to evaluate the cumulative effect of three years of consecutive minimum wage increases. Therefore, our approach combines a methodology that directly identifies minimum wage workers and applies it to different groups.

Our results show that after three consecutive yearly increases, from 2016 to 2018, during which time the minimum wage increased from $€ 8.65$ per hour to $€ 9.55$ per hour, the hours worked of minimum wage workers declined by approximately one hour per week, relative to workers who are paid just above the minimum wage. This equates to an elasticity of approximately -0.3. We identify heterogeneous impacts on hours worked among different groups of workers. Minimum wage workers in the industry sector and accommodation and food sector saw their hours reduce by approximately three hours per week and 2.5 hours per week, respectively. ${ }^{2}$ Finally, we find that non-Irish nationals on the minimum wage saw a reduction in hours worked of approximately 2.5 hours per week, which reflects the high concentration of such workers in the most affected sectors, namely the accommodation and food sector and the industry sector.

Findings relating to the impact on hours worked of a minimum wage change are often interpreted as a response by employers. However, in theory, reductions in hours worked could emerge as a consequence of two mechanisms (a) employers curtailing hours in order to mitigate labour cost increases or (b) workers consuming more leisure as a result of higher earnings. While we can observe the overall impact 
of minimum wage changes on hours worked, it is not possible to precisely disentangle the mechanisms that lie behind the estimated effects.

The paper proceeds as follows. Chapter 2 provides an overview of minimum wage policy in Ireland. Chapter 3 describes the data and presents some descriptive statistics. Chapter 4 describes the difference-in-differences methodology in detail. Chapter 5 presents our results and Chapter 6 concludes. 


\section{Minimum wages in Ireland}

A minimum wage was first introduced in Ireland in 2000 at a rate of $€ 5.58$ per hour. Following this, the minimum wage rate was steadily increased in subsequent years, reaching $€ 8.65$ per hour by 2007 . Coinciding with the onset of the global financial crisis, from 2008 onwards Ireland experienced a severe and prolonged economic downturn, with the unemployment rate reaching a high of 15 per cent in 2012. Coinciding with this economic downturn, there were no increases in the minimum wage for a period of almost nine years, such that the minimum wage in 2015 was the same as it had been in 2007 ( $€ 8.65$ per hour). ${ }^{3}$

As the economy recovered, a Low Pay Commission was established in Ireland in 2015. Their role is to make yearly recommendations to the Irish government on a minimum wage that is 'fair and sustainable' and will 'assist as many low-paid workers as possible without harming overall employment and competitiveness'. Following recommendations from the Low Pay Commission, the minimum wage was increased in January 2016 from $€ 8.65$ to $€ 9.15$ per hour. The 2016 minimum wage change was the first increase in the minimum wage since 2007. Based on recommendations from the Low Pay Commission, further increases to the minimum wage were implemented in 2017 (to €9.25 per hour), 2018 (to €9.55 per hour), 2019 (to $€ 9.80$ per hour), 2020 (to $€ 10.10$ per hour) and 2021 (€10.20 per hour).

Minimum wages are a common feature of advanced western democracies. Currently, 21 of the 27 EU Member States, along with the United Kingdom and the United States, have a statutory minimum wage. A recent comparative study by Redmond et al. (2021) benchmarked Irish minimum wage policy within an EU context. ${ }^{4}$ In nominal terms, Ireland has the second highest minimum wage in the EU. When measured in purchasing power standard terms, the Irish minimum wage is the sixth highest in the EU, behind Luxembourg, Germany, the Netherlands, Belgium and France. Using data for 2017 and 2018, Redmond et al. (2021) estimate that 9.6 per cent of employees in Ireland were paid the minimum wage. This compared to an average incidence of minimum wage employment across all countries studied of 10.5 per cent.

There was a short-lived reduction in the minimum wage in January 2011, from $€ 8.65$ to $€ 7.65$ per hour, which was reversed six months later (Redmond, 2020).

4 Redmond et al. (2021) analysed 14 countries: Ireland, Portugal, Germany, Poland, Hungary, Spain, United Kingdom, Luxembourg, Estonia, France, Latvia, Greece, Netherlands and Belgium. 



\section{CHAPTER 3}

\section{Data and descriptive statistics}

We use a dataset called the Earnings Analysis using Administrative Data Sources (EAADS), which links earnings from administrative sources to Labour Force Survey data. The data are administered by the Central Statistics Office (CSO) in Ireland. Earnings data are taken from official P35 tax records. The administrative earnings data are then linked to data from the Irish Labour Force Survey (LFS), which capture a range of employee characteristics including age, gender, education, marital status and sector of work. Importantly, for our analysis, it also captures the usual hours worked of the employee. Some restrictions are made on the sample of respondents included in EAADS. Respondents with missing information for any of the linked LFS variables are omitted. The data also exclude employees earning less than $€ 500$ per annum, employments with a duration of less than two weeks in a year and employment activity in agriculture (NACE code A), activities of households as employers (NACE code T) and activities of extraterritorial organisations and bodies (NACE code $U$ ). Earnings outliers with extremely high or low earnings are removed from the data. ${ }^{5}$ Finally, the EAADS focuses on the employee's principal employment. In the case of employees with multiple jobs, the principal employment, defined as the employment with the highest annual earnings, is included in the dataset.

We use seven years of repeated cross-sectional data, from 2012 to 2018. From 2012 to 2015 the minimum wage in Ireland was unchanged, at $€ 8.65$ per hour. As such, we have four pre-treatment years of data. In 2016, the minimum wage was increased by approximately 6 per cent, from $€ 8.65$ per hour to $€ 9.15$ per hour. There was a further small increase in 2017, from €9.15 to €9.25 per hour, and a further increase in 2018 to $€ 9.55$ per hour. As we describe in more detail in Chapter 4, we use a difference-in-differences estimator to evaluate the impact of a minimum wage change on hours worked. This is based on comparing a treatment group of low-paid workers, who were affected by minimum wage changes, to a control group consisting of relatively low-paid workers earning in excess of the minimum wage that were, therefore, not impacted by the minimum wage changes.

We calculate a worker's hourly wage rate by dividing their gross monthly income (from administrative sources) by their self-reported usual hours of work. We define our treatment group, the minimum wage workers, as those earning above $€ 6$ and less than $€ 10.03$ per hour. The $€ 10.03$ cut-off equates to the 2018 minimum wage,

The cut-off used by the CSO to define outliers is Q3+3*IQR for high earners or Q1-3*IQR for low earners. Therefore, these outliers are so extreme that they would be excluded from our analysis even if they were included in the dataset. 
of $€ 9.55$ per hour, plus 5 per cent. The plus 5 per cent is to add a degree of flexibility as the hourly wage is estimated using self-reported hours. We implement a lower bound of $€ 6$ per hour as it approximately equals the lowest legally permitted subminimum wage rate that was operational over the time period covered in the analysis. ${ }^{6}$ We chose this cut-off to limit the possibility of capturing low-paid employees who are working for non-compliant employers and are therefore being illegally paid a very low wage rate. When analysing the impact of a minimum wage change, it would not be appropriate to include such employees in the analysis given that their employers may be non-compliant to begin with. The $€ 6$ lower bound also excludes individuals whose calculated wage is implausibly low, suggesting that for these individuals there may be issues with either the gross weekly earnings or reported hours of work. There are individuals in the dataset that report very high weekly hours of work. We exclude the top one percentile of the hours worked distribution, leaving us with employees working on or below 60 hours per week. We define our control group as employees earning above $€ 10.03$ but below $€ 15$ per hour. ${ }^{7}$

As noted by Stewart (2012), choosing a control group for minimum wage studies involves a trade-off. Choosing a control group higher up the wage distribution reduces the risk of the control group being affected by spillover effects associated with a minimum wage change. However, the higher up the distribution, the less similar the control group will be to the treatment group. Our identification strategy seeks to balance these two issues by ensuring that individuals in our control group should not be directly impacted by the minimum wage change, but are still relatively low-paid and therefore likely to be similar to the treatment group based on characteristics such as education, age and experience.

In Table 3.1 we present descriptive statistics for our treatment and control groups. To help with exposition, we will refer to the treatment group as minimum wage employees, as this is the low-paid group that is likely to be directly impacted by minimum wage increases. We show the averages for both groups in two time periods, the years where no minimum wage change occurred (2012 to 2015) and the years where the minimum wage was increased (2016 to 2018). Comparing the treatment and control groups, we see that the minimum wage employees are slightly younger, less likely to have a tertiary education, less likely to be married, and more likely to be working in a services sector job (defined as retail, accommodation or food). 
TABLE 3.1 DESCRIPTIVE STATISTICS OF MINIMUM WAGE AND HIGHER PAID (NON-MW EMPLOYEES)

\begin{tabular}{|l|c|c|c|c|}
\hline & \multicolumn{2}{|c|}{ MW Employees } & \multicolumn{2}{c|}{ Non-MW Employees } \\
\hline & $\mathbf{2 0 1 2 - 2 0 1 5}$ & $\mathbf{2 0 1 6 - 2 0 1 8}$ & $\mathbf{2 0 1 2 - 2 0 1 5}$ & $\mathbf{2 0 1 6 - 2 0 1 8}$ \\
\hline Hours worked & 32.0 & 32.2 & 33.0 & 33.5 \\
\hline Age & 34.5 & 35.2 & 37.6 & 38.4 \\
\hline Male (\%) & 38.7 & 41.2 & 44.7 & 45.4 \\
\hline Tertiary education (\%) & 28.3 & 25.3 & 34.4 & 32.5 \\
\hline Married (\%) & 36.4 & 34.0 & 45.9 & 43.6 \\
\hline Services (\%) & 46.5 & 45.0 & 34.8 & 34.2 \\
\hline Observations & 8,299 & 4,723 & 17,575 & 11,328 \\
\hline
\end{tabular}

Source: EAADS. Authors' own calculations.

With regard to changes over time in the characteristics of employees, we first look at hours worked which is the outcome of interest in this study. There was an increase of 0.2 hours per week among the minimum wage workers compared to an increase of 0.5 hours per week among the non-minimum wage workers. Note that one could construct a basic difference-in-differences estimate which would simply compare the average hours change in both groups, pre- and post-minimum wage change. This would give an estimate of -0.3 hours $(0.2-0.5)$, indicating the hours worked of the minimum wage workers increased by less than the hours worked of the control group. However, this type of basic estimate is problematic, as it fails to allow for the possibility of divergent pre-treatment dynamics, does not allow for the flexible identification of results in post-treatment years, does not control for the possibility of differences in the composition of treatment and control groups over time and does not indicate statistical significance. We formally address these issues later in the paper by using a fully flexible difference-indifferences estimator which includes a range of control variables. The other characteristics reported in Table 3.1 were relatively stable over time. There was a slight increase in the average age and the percentage of males in both groups over time, while there was a decrease in the percentage with tertiary education, the percentage that were married and the percentage in services occupations. The direction of these changes was the same in both the treatment and control groups.

We calculate the incidence of minimum wage employment using the LFS-EAADS dataset and compare it to two other estimates that have been calculated using different data sources. Firstly, Redmond et al. (2021), calculate the incidence of minimum wage employment using EU-SILC data for Ireland, grouping together the years 2017 and 2018. They consider a person to be a minimum wage employee if they were earning on or below 105 per cent of the minimum wage. Redmond et al. (2021) estimate that 10.6 per cent of employees in Ireland were on the minimum wage during the period 2017 and 2018. Using Labour Force Survey (LFS) data, the Irish Central Statistics Office estimates that 8.6 per cent and 7.6 per cent of 
employees were minimum wage workers in 2017 and 2018 respectively. ${ }^{8}$ The incidence of minimum wage employment using our LFS-EAADS data for 2017 and 2018 combined is 9.3 per cent. ${ }^{9}$ Therefore, the estimated incidence of minimum wage employment using the LFS-EAADS data is consistent with previous estimates using different data sources. Our estimate of 9.3 per cent for 2017 and 2018 lies between the slightly higher EU-SILC estimate and slightly lower LFS estimate. 


\section{CHAPTER 4}

\section{Methodology}

We use a fully flexible difference-in-differences estimator, proposed by Mora and Reggio (2015), to examine the impact of recent changes to the Irish minimum wage on hours worked. Unlike other basic difference-in-differences estimators, the fully flexible estimator does not impose parallel pre-treatment trends. Instead, the slope and intercept are free to vary for all pre-treatment and post-treatment time periods. Mora and Reggio (2015) propose a test for common trends, which essentially tests whether the treatment and control groups, which are free to take on different pre-treatment trends, actually display common pre-treatment dynamics. The post-treatment periods are also fully flexible, allowing us to examine the post-treatment dynamics relating to three years of minimum wage changes.

More formally, the fully flexible difference-in-differences estimator is implemented with the following regression,

$E\left(Y_{i t} \mid D_{i}, X_{i}\right)=\delta+X_{i t}^{\prime} \beta+\sum_{\tau=t_{2}}^{T} \delta_{\tau} I_{t}^{\tau}+\gamma^{D} D_{i}+\sum_{\tau=t_{2}}^{T} \alpha_{\tau} \cdot I_{t}^{\tau} \cdot D_{i}+\varepsilon_{i t}$

where the outcome variable, $Y_{i t}$, is the usual weekly hours worked by individual $i$ in year $t . D_{i}$ is the treatment dummy variable which equals one for low-paid workers likely to be directly impacted by the minimum wage increase (the treatment group) and zero for other low-paid workers earning above the minimum wage (the control group). ${ }^{10}$ The variable $I_{t}^{\tau}$ is a dummy variable for year $\tau$ and $X_{i t}{ }^{\prime}$ is a vector of additional control variables including age, education, gender, marital status, time with current employer, firm size, region, nationality (Irish or non-Irish) and sector of employment. The final term on the right-hand side of Equation (1) is what makes the model fully flexible; each year dummy is interacted with the treatment dummy. This may include multiple pre-treatment and multiple post-treatment years.

For ease of exposition, we will accompany our explanation of the estimator shown in Equation (1) with a hypothetical illustrative example (Figure 4.1). We will begin by assuming that there are three pre-treatment periods and one post-treatment period. ${ }^{11}$ Let us assume that time periods $1-3$ are the pre-treatment years and time period 4 is the post-treatment year. The quantity of interest that we wish to capture with our difference-in-differences estimator is the difference in average outcomes among the treated group, pre- and post-treatment, minus the difference

10 As defined in Chapter 2, the treatment group consist of workers earning less than $€ 10.03$ per hour and the control group consists of those earning between $€ 10.03$ and $€ 15$ per hour.

11 Note that Equation (1) allows for multiple post-treatment periods, which we will discuss later in the context of our application of the method. 
in outcomes among the control group over the same period. Given the last pretreatment year is period 3 and the post-treatment year is period 4, from Equation (1) we get,

$$
\begin{aligned}
& {[E(Y \mid D=1, \tau=4)-E(Y \mid D=1, \tau=3)]-[E(Y \mid D=0, \tau=4)-} \\
& E(Y \mid D=0, \tau=3)]=\alpha_{4}-\alpha_{3}
\end{aligned}
$$

The estimate in Equation (2), which is a linear combination of the interaction parameters in Equation (1), corresponds to the standard difference-in-differences approach, whereby one examines changes in outcomes from the last pretreatment year (year 3) to the post-treatment year (year 4). Graphically, it would correspond to $(A-B)-(E-F)$ in our illustrative example in Figure 4.1.12 As the estimated treatment effect is a linear combination of the interaction coefficients, computation of the standard errors of the treatment effect needs to take this into account. ${ }^{13}$

Note, however, that we have not yet mentioned pre-treatment dynamics. It may be that the outcomes of the treated and control group were diverging before the treatment, for example from period 2 to period 3 . In the context of a differencein-differences setup, this is important, because if the outcomes of the treated and control group were diverging before the treatment occurred, then we cannot be confident that the difference in outcomes post-treatment is attributable to the treatment itself. Referring to the illustrative example (Figure 4.1), we could incorporate possible pre-treatment divergence into our estimate, by estimating $[(A-B)-(E-F)]-[(B-C)-(F-G)]$. In our hypothetical example, we can see that the outcome for the treated group increased by more than the control group in the pre-treatment periods 2 to 3 , captured by (B-C)-(F-G), and this is subtracted from the original estimate of $(A-B)-(E-F)$. Therefore, accounting for this leads to a lower estimated treatment effect (compared to the first estimate of $(A-B)-(E-F)$ ). The analogous estimate using Equation (1) is,

$$
\begin{aligned}
& \{[E(Y \mid D=1, \tau=4)-E(Y \mid D=1, \tau=3)]-[E(Y \mid D=0, \tau=4)- \\
& E(Y \mid D=0, \tau=3)]\}-\{[E(Y \mid D=1, \tau=3)-E(Y \mid D=1, \tau=2)]- \\
& [E(Y \mid D=0, \tau=3)-E(Y \mid D=0, \tau=2)]\}=\alpha_{4}-2 \alpha_{3}-\alpha_{2}(3)
\end{aligned}
$$




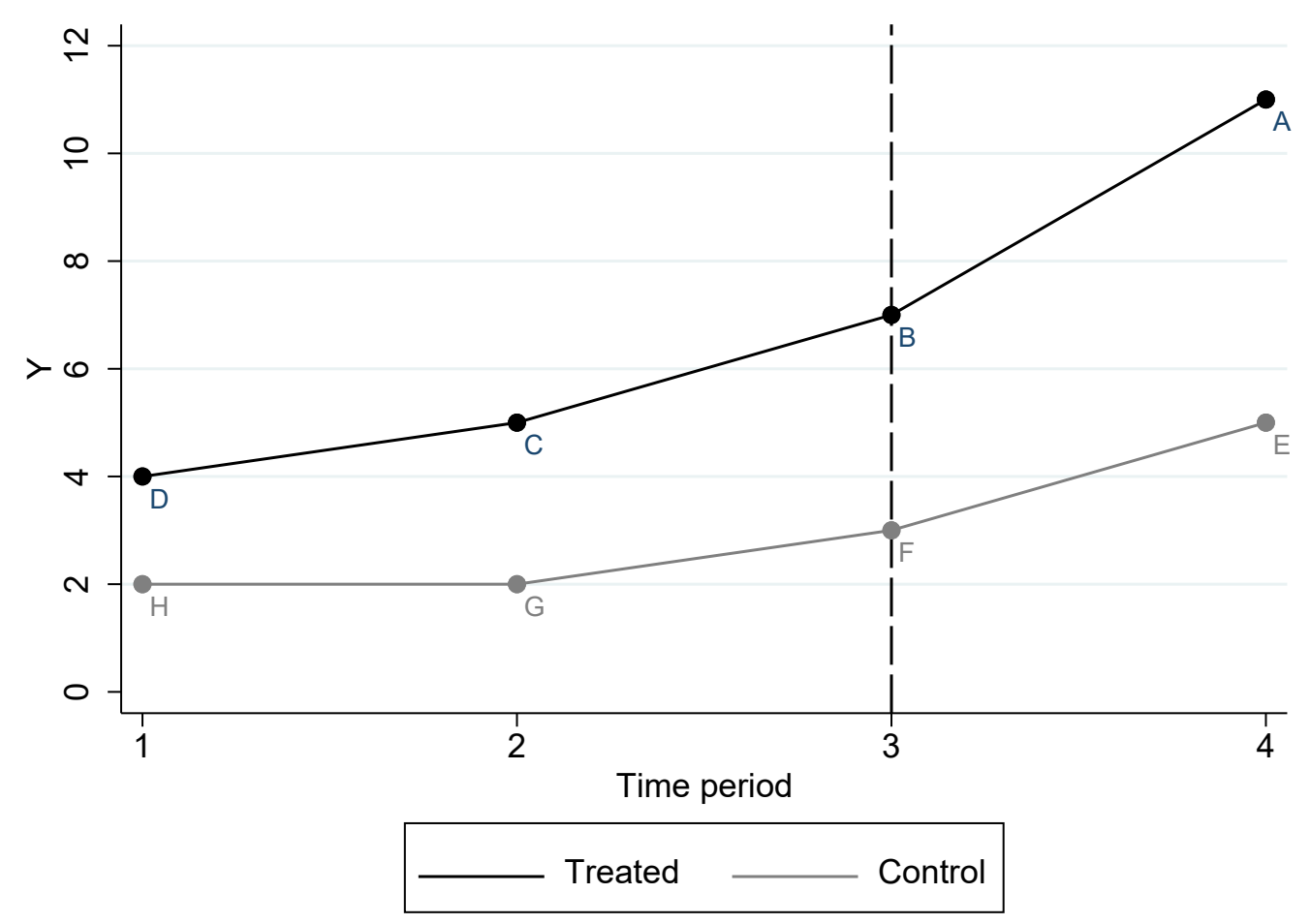

Finally, in the discussion of pre-treatment dynamics, it is important to take account of potentially different acceleration between the treated and control group outcomes. For example, if the treated group outcomes are accelerating faster than the control group outcomes (pre-treatment), as appears to be the case in the illustrative example (Figure 4.1), then in the absence of treatment, assuming that the treated group would have continued the trajectory observed from periods 2 to 3 may not be accurate; with different acceleration in the treatment and control groups, then in the absence of treatment, the increase from period 3 to 4 may be greater than the increase from period 2 to 3 , and therefore, the estimate in Equation (3) would be an overestimate. With reference to the illustrative example (Figure 4.1), different acceleration between the groups can be taken into account by estimating, [(A-B)-(E-F)]-[(B-C)-(F-G)] and then subtracting [(B-C)-(F-G)]-[(C-D)$(\mathrm{G}-\mathrm{H})]$. The analogous estimate using Equation (1) is,

$$
\begin{aligned}
& \{[E(Y \mid D=1, \tau=4)-E(Y \mid D=1, \tau=3)]-[E(Y \mid D=0, \tau=4)- \\
& E(Y \mid D=0, \tau=3)]\}-\{[E(Y \mid D=1, \tau=3)-E(Y \mid D=1, \tau=2)]- \\
& [E(Y \mid D=0, \tau=3)-E(Y \mid D=0, \tau=2)]\}-\{[E(Y \mid D=1, \tau=3)- \\
& E(Y \mid D=1, \tau=2)]-[E(Y \mid D=0, \tau=3)-E(Y \mid D=0, \tau=2)]\}- \\
& \{[E(Y \mid D=1, \tau=2)-E(Y \mid D=1, \tau=1)]-[E(Y \mid D=0, \tau=2)- \\
& E(Y \mid D=0, \tau=1)]\}=\alpha_{4}-3 \alpha_{3}+3 \alpha_{2}
\end{aligned}
$$


Note that in the presence of common pre-treatment trends, the estimates shown in Equations (2) to (4) would be the same. More formally, equal pre-treatment trends between the treated and control groups implies that $\alpha_{\tau}=0$ for all $\tau \leq 3$. As noted by Mora and Reggio (2015), the test of the null hypothesis of common pre-treatment trends, i.e. that $\alpha_{\tau}=0$ for all $\tau \leq 3$, is a test for the simultaneous equivalence of all of the estimates shown in Equations (2) to (4). We report the relevant $p$-values for each difference-in-differences specification to indicate whether common pre-treatment dynamics exist. ${ }^{14}$

In our application of this estimator, in addition to multiple pre-treatment years, we have multiple post-treatment years. In our data there was no minimum wage increase from 2012 to 2015 (pre-treatment years). However, the minimum wage was increased in 2016, with further incremental increases in 2017 and 2018. Therefore 2016-2018 are post-treatment years. It is important to discuss the posttreatment years in the context of our estimator, in order to get a clear understanding on how we interpret the results. Consider again the illustrative graph (Figure 4.1). Suppose there were two post-treatment years ( 3 and 4 ), so that the vertical line was now positioned at period 2 on the $x$-axis. The estimate for the first post-treatment time point, period 3 , is $(B-C)-(F-G)$. The estimate for the second post-treatment time point, period 4 , is $(A-C)-(E-G)$. This can be viewed as a cumulative impact of the minimum wage increases across both post-treatment years. It is important that we view our results in this way. For example, consider a scenario where the treatment and control groups experience common pretreatment dynamics. When treatment occurs (i.e. the minimum wage starts to increase in 2016), the outcomes may begin to diverge, however not to the extent that we observe a statistically significant effect in 2016. Likewise, if the additional small incremental change in 2017 leads to a further small effect on the outcome, then comparing 2017 to 2016 alone may not indicate a statistically significant result. Finally, the same could happen with the additional incremental change in 2018, and again, simply comparing 2018 to 2017 may show a relatively small and perhaps not significant result. Meanwhile, the incremental divergence between the treatment and control groups over the three years may cumulate to a substantial impact, which potentially could be missed if all we examine are the changes associated with each year pairing.

In our baseline specification, we are defining our treatment group as low-paid workers earning less than $€ 10.03$ per hour. As such, we can be confident that we are identifying low-paid workers that are likely to be impacted by the minimum wage changes. Note that our $€ 10.03$ cut-off is based on the 2018 minimum wage of $€ 9.55$ per hour ( 5 per cent), as we are ultimately interested in the final effect 
of three rate rises which culminate in this year. However, recall that following several years of no change, the minimum wage increased in 2016 from $€ 8.65$ per hour to $€ 9.15$ per hour, and in 2017 to $€ 9.25$ per hour, before increasing to $€ 9.55$ per hour in 2018. Therefore, we could choose a cut-off of $€ 9.61$ ( $€ 9.15+5$ per cent) for 2016, a cut-off of $€ 9.71$ ( $€ 9.25+5$ per cent) for 2017 , while using the $€ 10.03$ cut-off in 2018 only. This would mean, for example, that employees in the 10c window of €9.61-€9.71 in 2016 would be categorised as being in the control group for the purpose of estimating the 2016 effect, while being in the treatment group for estimating the 2017 effect. However, choosing a control group that is too close to the treatment group runs the risk of the control group being impacted by spillover effects (Stewart, 2012; Redmond et al., 2021), as well as the related risk of misallocating minimum wage workers as control group workers. Consistently applying the $€ 10.03$ cut-off helps to avoid these issues and has the advantage of being more intuitive and straightforward to estimate as the control and treatment groups remain constant over time. ${ }^{15}$ However, we verify the robustness of our baseline results by estimating separate models for 2016 and 2017, using the associated cut-offs based on the prevailing minimum wage rate in each year ( $€ 9.61$ for 2016 and $€ 9.71$ for 2017). We show that the results are consistent across all specifications.

15 Choosing the higher cut-off, however, leads to the possibility that we include some non-minimum wage workers as part of the control group in the earlier years, which could potentially attenuate the hours effects for 2016 and 2017. However, the estimates for 2018 would not be impacted. 



\section{CHAPTER 5}

\section{Results}

We begin by examining the effect of a minimum wage increase on all minimum wage workers. Before discussing the results from our difference-in-differences estimation, it is useful to graphically display the average outcomes among the treatment and control groups over time (Figure 5.1). From 2012 to 2015, the minimum wage was unchanged. During this period, we see that the average hours worked for both the treatment and control group followed a very similar trend. This provides descriptive evidence of parallel pre-treatment trends. The minimum wage was increased in 2016, and again in 2017 and 2018. The vertical line distinguishes the pre-treatment period from the post-treatment period. While there is no apparent impact in 2016, we see that by 2018, a gap has opened up between the hours worked of minimum wage workers and those paid just above the minimum wage. This suggests that the cumulative minimum wage increases from 2016 to 2018 led to a fall in the hours worked of minimum wage workers, relative to workers paid just above the minimum wage.

\section{FIGURE 5.1 AVERAGE WEEKLY HOURS WORKED (2012 TO 2018)}

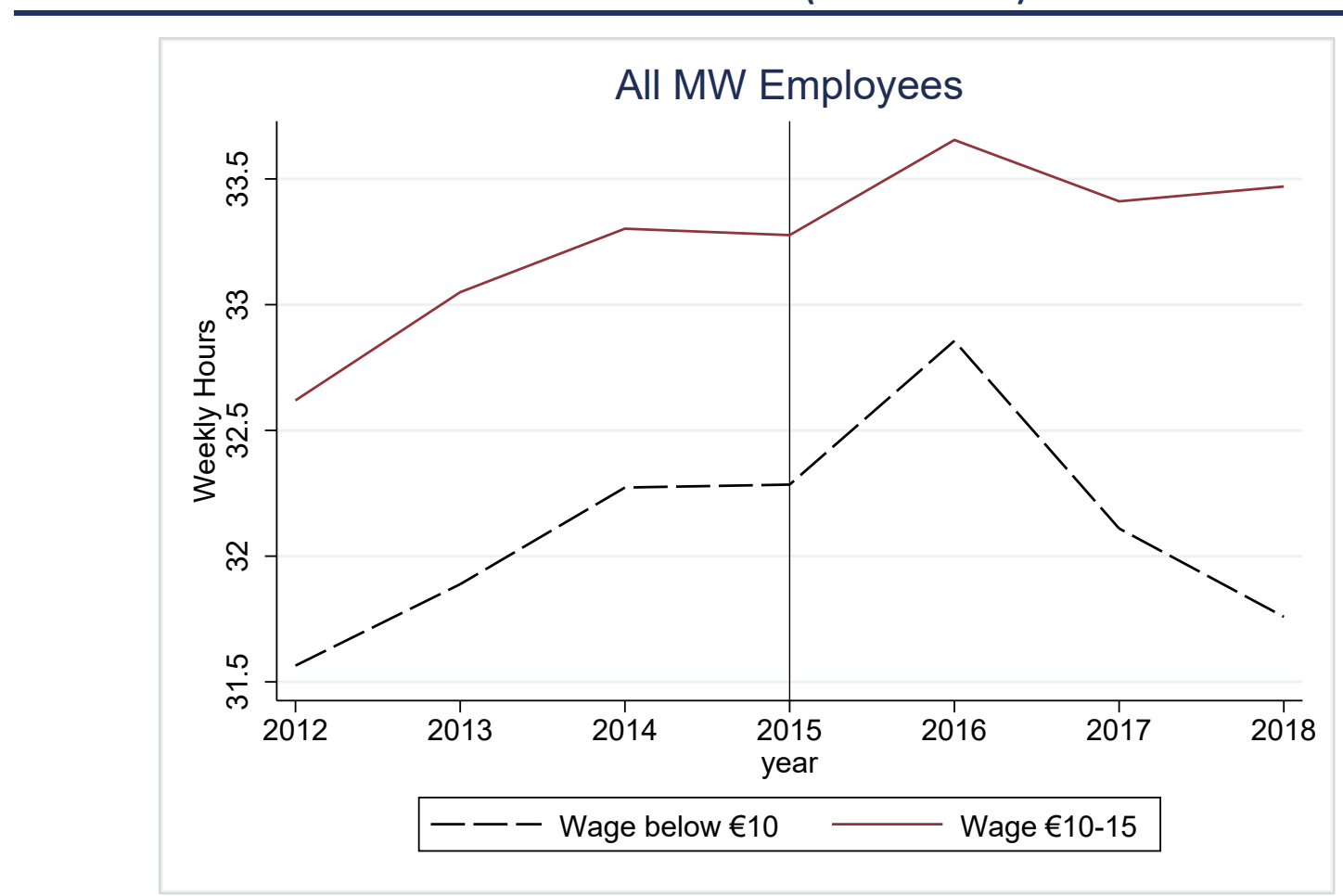

Source: Authors' analysis.

To formally estimate the impact of the minimum wage increases, we estimate Equation (1) for all minimum wage employees. The results are shown in Table 5.1. 
Recall that our estimator allows for flexible post-treatment dynamics and, as such, we show the separate difference-in-differences estimates for each year from 2016 to 2018. The estimate for 2018 indicates that, compared to the time period before the minimum wage increase, minimum wage workers in 2018 saw a one-hour (approximately) reduction in their weekly hours worked relative to the control group. The estimate for 2017, while negative, is not statistically significant, and the estimate for 2016 is close to zero and not significant. Our difference-in-differences estimates correspond to the graphical evidence shown in Figure 5.1. With regard to the other control variables, being male, having high education and being married are associated with working longer hours, as is increased job tenure and living in the Dublin region. Working in the services sector, being an Irish national and working in a firm with less than 100 employees is associated with working fewer hours.

While Figure 5.1 shows graphical evidence of parallel pre-treatment trends, we report the p-value from the Mora and Reggio (2015) test for common pretreatment dynamics, discussed in Chapter 3. ${ }^{16}$ The null hypothesis is the existence of common pre-treatment dynamics. Therefore, a 'low' p-value below 0.10 would lead us to reject the null hypothesis of common pre-treatment dynamics at the 10 per cent level. In Table 5.1, the p-value is 0.48 . As such, we conclude that common pre-treatment dynamics exist, which is consistent with Figure 5.1 and supports the validity of our estimator. 


\begin{tabular}{|c|c|}
\hline VARIABLES & Hours \\
\hline \multicolumn{2}{|l|}{ DiD Estimates } \\
\hline \multirow[t]{2}{*}{ DiD - 2018} & $-0.95 * *$ \\
\hline & $(0.46)$ \\
\hline \multirow[t]{2}{*}{ DiD - 2017} & -0.59 \\
\hline & $(0.42)$ \\
\hline \multirow[t]{2}{*}{ DiD - 2016} & 0.04 \\
\hline & $(0.08)$ \\
\hline \multicolumn{2}{|l|}{ Control Variables } \\
\hline \multirow[t]{2}{*}{ Male } & $7.05 * * *$ \\
\hline & $(0.10)$ \\
\hline \multirow[t]{2}{*}{ High education } & $5.16 * * *$ \\
\hline & $(0.16)$ \\
\hline \multirow[t]{2}{*}{ Medium education } & $2.21 * * *$ \\
\hline & $(0.15)$ \\
\hline \multirow[t]{2}{*}{ Married } & $0.41 * * *$ \\
\hline & $(0.11)$ \\
\hline \multirow[t]{2}{*}{ Services sector } & $-2.45^{* * *}$ \\
\hline & $(0.10)$ \\
\hline \multirow[t]{2}{*}{ Irish national } & $-1.76 * * *$ \\
\hline & $(0.05)$ \\
\hline \multirow[t]{2}{*}{ Experience (log years) } & $1.41 * * *$ \\
\hline & $(0.05)$ \\
\hline \multirow[t]{2}{*}{ Firm size (<100 employees) } & $-3.28 * * *$ \\
\hline & $(0.11)$ \\
\hline \multirow[t]{2}{*}{ Dublin region } & $0.20 * * *$ \\
\hline & $(0.01)$ \\
\hline \multirow[t]{2}{*}{ Age } & $-0.08 * * *$ \\
\hline & $(0.01)$ \\
\hline Year dummies & yes \\
\hline Pre-dynamics: $p$-value & 0.48 \\
\hline Observations & 38,599 \\
\hline
\end{tabular}

Source: Authors' analysis.

Note: $\quad$ Robust standard errors in parentheses. $* * * p<0.01, * * p<0.05, * p<0.1$.

Next, we investigate heterogeneous effects across groups of minimum wage workers. It is possible that certain groups of minimum wage workers experience negative employment effects while other groups experience little to no effects. Focusing on the estimates for all minimum wage workers would fail to pick this up. In Table 5.2 we present the difference-in-differences estimates for a wide range of subgroups of minimum wage employees. We present separate results for minimum wage workers on temporary contracts, non-Irish nationals on the minimum wage, and minimum wage workers in different sectors and regions. In addition to showing the difference-in-differences estimates, we also show the 
p-value associated with the Mora and Reggio (2015) test of common pre-treatment dynamics.

Previous work by McGuinness and Redmond (2019) found that minimum wage workers on temporary contracts in Ireland experienced a reduction in hours following the 2016 minimum wage increase. The magnitude of the reduction was approximately three hours per week. As noted by McGuinness and Redmond (2019), focusing on temporary contract workers is of interest because temporary contracts are more flexible than permanent contracts (Booth et al., 2002) and, as such, employers may find it easier to make adjustments at the intensive margin for these workers. Moreover, temporary contract workers have been found to be 60 per cent more likely to work unpaid overtime compared to permanent contract workers (Engellandt and Riphahn, 2005). Therefore, employers may be able to reduce their hours while retaining a similar level of effort. McGuinness and Redmond (2019) did not have access to wage data and had to rely on earnings decile data combined with data on hours worked to try and identify low-paid workers that were likely to be impacted by the minimum wage rise. ${ }^{17}$ We test the findings of McGuinness and Redmond (2019) for temporary contract workers using our administrative earnings data. Our results, shown in the first row of estimates in Table 5.2, are consistent with McGuinness and Redmond (2019); we find that following the minimum wage increase in 2016, minimum wage workers on temporary contracts experienced an hours reduction of approximately 2.5 hours per week relative to workers paid just above the minimum wage on temporary contracts. However, by 2018 , this effect appears to have dissipated, indicating that the change in hours worked in 2018 compared to 2015 among minimum wage workers on temporary contracts, was roughly equivalent to the change in hours worked over the same period among slightly higher paid workers on temporary contracts. ${ }^{18}$

For the sectoral analysis, we examine six NACE sectors: industry; accommodation and food; wholesale and retail; administrative and support; health and social activities; and arts, entertainment and recreation. Minimum wage workers are not spread equally across sectors, and consequently many sectors have too few workers to conduct meaningful analyses. ${ }^{19}$ The two largest minimum-wage employing sectors are wholesale and retail and accommodation and food. These two sectors alone employ approximately half of all minimum wage workers in Ireland. However, other sectors such as financial services or public administration

17 McGuinness and Redmond used Irish Labour Force Survey data, which did report exact earnings data, but reported income decile data.

18 Similar to the Labour Force Survey which directly asks people whether they are minimum wage workers, it should be noted that the majority of minimum wage workers in our dataset are classified as having a permanent contract.

19 Some sectors contain so few minimum wage workers that any attempted analysis would not meet the required statistical disclosure agreement, in terms of sample size, required by the Central Statistics Office in Ireland. 
employ very low numbers of minimum wage workers and therefore are not included in our analysis.

The results in Table 5.2 indicate that minimum wage employees in the industry sector and in the accommodation and food sector were affected by the minimum wage changes. In 2018, minimum wage workers in the industry sector were working three hours less per week compared to their higher paid counterparts. Negative hours coefficients were also observed in 2016 and 2017, of 2.09 and 1.64 hours respectively, however the 2017 coefficient is not statistically significant at conventional levels. ${ }^{20}$ For minimum wage workers in accommodation and food, we see a series of year-on-year reductions in hours worked from 2016 to 2018. While the coefficients in 2016 and 2017 of -0.18 and -1.17 are not statistically significant, by 2018 the effect is statistically significant, and indicates that minimum wage workers in the accommodation and food sector were working 2.5 fewer hours than their higher paid counterparts. These results show the value of our methodology. By utilising several post-treatment years, and by allowing for fully flexible posttreatment dynamics, we can see the hours effects gradually becoming more and more pronounced as the minimum wage rises over three consecutive time periods. The p-values shown in Table 5.2 indicates common pre-treatment dynamics for each sector.

We estimate our difference-in-differences model separately for each of the five regions that are captured in the data. While the individual regional coefficients are not statistically significant, note that in 2018 the coefficient was approximately -1 for each region, which is similar to the overall estimated effect in Table 5.1. ${ }^{21}$ This suggests that no one region in particular is the driving force behind the overall effect that we detect when pooling all minimum wage workers together. 
TABLE 5.2 DIFFERENCE-IN-DIFFERENCES ESTIMATES (2016 TO 2018)

\begin{tabular}{|c|c|c|c|c|}
\hline & 2018 & 2017 & 2016 & $\begin{array}{l}\text { Pre-dynamics: } \\
\text { p-value }\end{array}$ \\
\hline $\begin{array}{l}\text { Temporary contract } \\
\mathrm{N}=3,983\end{array}$ & $\begin{array}{c}0.65 \\
(1.33)\end{array}$ & $\begin{array}{l}-2.11 \\
(1.39)\end{array}$ & $\begin{array}{l}-2.45^{*} \\
(1.50)\end{array}$ & 0.52 \\
\hline \multicolumn{5}{|l|}{ Sectors } \\
\hline $\begin{array}{l}\text { Industry } \\
\mathrm{N}=4,572\end{array}$ & $\begin{array}{l}-3.02 * * * \\
(1.18)\end{array}$ & $\begin{array}{l}-1.64 \\
(1.10)\end{array}$ & $\begin{array}{l}-2.09 * * \\
(1.07)\end{array}$ & 0.99 \\
\hline $\begin{array}{l}\text { Accommodation \& food } \\
N=5,014\end{array}$ & $\begin{array}{l}-2.56^{* *} \\
(1.15)\end{array}$ & $\begin{array}{l}-1.17 \\
(1.14)\end{array}$ & $\begin{array}{l}-0.18 \\
(1.22)\end{array}$ & 0.74 \\
\hline $\begin{array}{l}\text { Wholesale \& retail } \\
\mathrm{N}=10,483\end{array}$ & $\begin{array}{c}0.50 \\
(0.83)\end{array}$ & $\begin{array}{l}-0.47 \\
(0.81)\end{array}$ & $\begin{array}{c}0.67 \\
(0.84)\end{array}$ & 0.47 \\
\hline $\begin{array}{l}\text { Admin \& support } \\
\mathrm{N}=2,729\end{array}$ & $\begin{array}{c}2.31 \\
(1.67)\end{array}$ & $\begin{array}{c}1.30 \\
(1.64)\end{array}$ & $\begin{array}{l}1.05 \\
(1.74)\end{array}$ & 0.19 \\
\hline $\begin{array}{l}\text { Health \& social activities } \\
\mathrm{N}=4,293\end{array}$ & $\begin{array}{l}-1.66 \\
(1.33)\end{array}$ & $\begin{array}{l}-1.96 \\
(1.23)\end{array}$ & $\begin{array}{l}-0.11 \\
(1.28)\end{array}$ & 0.79 \\
\hline $\begin{array}{l}\text { Arts, entertainment \& recreation } \\
\mathrm{N}=2,145\end{array}$ & $\begin{array}{l}-1.56 \\
(1.89)\end{array}$ & $\begin{array}{c}1.06 \\
(1.74)\end{array}$ & $\begin{array}{c}0.31 \\
(1.94)\end{array}$ & 0.19 \\
\hline \multicolumn{5}{|l|}{ Regions } \\
\hline $\begin{array}{l}\text { Dublin } \\
N=9,145\end{array}$ & $\begin{array}{l}-1.12 \\
(0.91)\end{array}$ & $\begin{array}{l}-1.34 \\
(0.89)\end{array}$ & $\begin{array}{c}0.20 \\
(0.91)\end{array}$ & 0.06 \\
\hline $\begin{array}{l}\text { Rest of Leinster } \\
N=10,317\end{array}$ & $\begin{array}{l}-1.03 \\
(0.83)\end{array}$ & $\begin{array}{l}-0.91 \\
(0.82)\end{array}$ & $\begin{array}{c}0.16 \\
(0.91)\end{array}$ & 0.90 \\
\hline $\begin{array}{l}\text { Munster } \\
\mathrm{N}=11,923\end{array}$ & $\begin{array}{l}-0.79 \\
(0.82)\end{array}$ & $\begin{array}{l}-0.02 \\
(0.78)\end{array}$ & $\begin{array}{l}-0.36 \\
(0.82)\end{array}$ & 0.61 \\
\hline $\begin{array}{l}\text { Connacht } \\
\mathrm{N}=4,465\end{array}$ & $\begin{array}{l}-1.14 \\
(1.25)\end{array}$ & $\begin{array}{l}-0.57 \\
(1.16)\end{array}$ & $\begin{array}{l}-0.17 \\
(1.20)\end{array}$ & 0.72 \\
\hline $\begin{array}{l}\text { Ulster } \\
\mathrm{N}=\mathbf{2 , 7 4 9}\end{array}$ & $\begin{array}{l}-0.52 \\
(1.52)\end{array}$ & $\begin{array}{l}-0.93 \\
(1.41)\end{array}$ & $\begin{array}{c}0.43 \\
(1.56)\end{array}$ & 0.75 \\
\hline $\begin{array}{l}\text { Non-Irish Nationals } \\
N=6,087\end{array}$ & $\begin{array}{l}-2.48^{* *} \\
(1.03)\end{array}$ & $\begin{array}{l}-2.49 * * * \\
(0.96)\end{array}$ & $\begin{array}{l}-1.15 \\
(1.00)\end{array}$ & 0.42 \\
\hline
\end{tabular}

Source: Authors' analysis based on Earnings, Hours and Employment Costs data.

Note: Robust standard errors in parentheses ${ }^{* * *} p<0.01,{ }^{* *} p<0.05,{ }^{*} p<0.1$. We test for common pre-treatment dynamics as outlined in Chapter 3, using the Mora-Reggio test. All of the specifications, except the Dublin region specification, display common pretreatment dynamics.

Finally, we estimate the model separately for non-Irish nationals. Our analysis shows that by 2018 , non-Irish minimum wage workers were working three hours less than their higher paid, non-Irish counterparts. The finding for non-Irish nationals reflects the fact that many non-Irish minimum wage workers are located in the sectors that appear to be most affected in terms of changes to hours, namely the industry sector and accommodation and food sector. Approximately 33 per cent of non-Irish minimum wage workers are in the accommodation and food sector, compared to just 17 per cent of Irish minimum wage workers. The industry sector employs approximately 13 per cent of non-Irish minimum wage workers, compared to approximately 8 per cent of Irish minimum wage workers.

The evidence presented in Table 5.2 indicates that three groups of minimum wage workers experienced a significant decline in hours worked - those in the industry sector, those in the accommodation and food sector, as well as non-Irish nationals. 
The results from Table 5.2 are also consistent with common pre-treatment dynamics for these groups. In Figures 5.2 to 5.4 we present the corresponding graphical results for the three groups that display statistically significant effects. In all graphs we see that, before the minimum wage increases (pre-2016), the average hours worked for the treatment and control groups displayed similar patterns. The graph for the industry sector (Figure 5.2 ) shows a substantial and immediate effect following the first minimum wage increase in 2016. A gap appeared between the treatment and control group, and by 2018, minimum wage workers in the industry sector were working approximately three hours less per week compared to their higher paid counterparts. This is consistent with the coefficients and the test for pre-treatment dynamics in Table 5.2. For minimum wage workers in accommodation and food (Figure 5.3) and for non-Irish nationals on the minimum wage (Figure 5.4), there is no immediate effect in 2016, but by 2018 there is a gap of approximately two hours per week between minimum wage workers and workers paid just above the minimum wage.

FIGURE 5.2 AVERAGE WEEKLY HOURS WORKED FOR INDUSTRY SECTOR EMPLOYEES (2012 TO 2018)

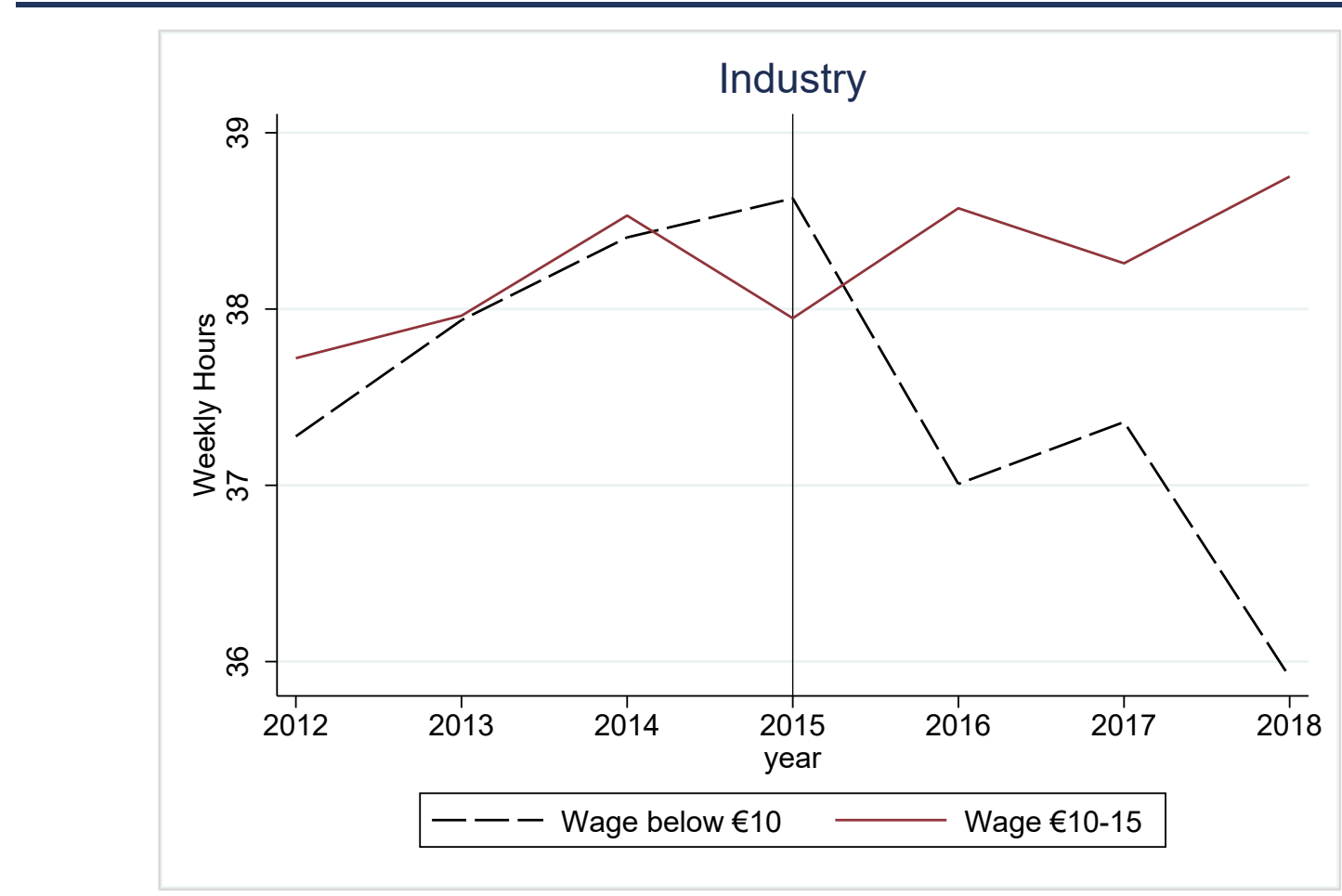

Source: Authors' analysis. 
FIGURE 5.3 AVERAGE WEEKLY HOURS WORKED FOR ACCOMMODATION AND FOOD SECTOR EMPLOYEES (2012 TO 2018)

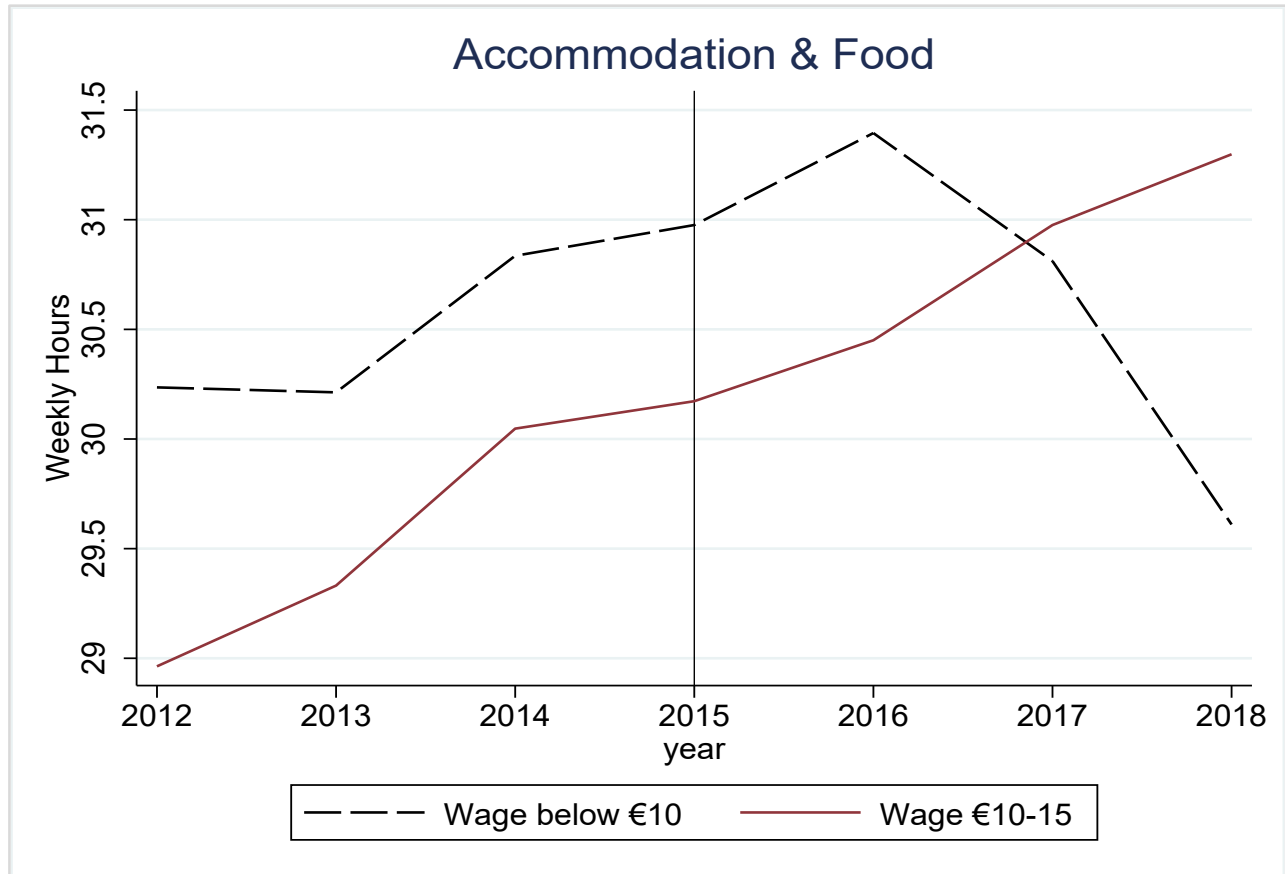

Source: Authors' analysis.

FIGURE 5.4 AVERAGE WEEKLY HOURS WORKED FOR NON-NATIONAL EMPLOYEES (2012 TO 2018)

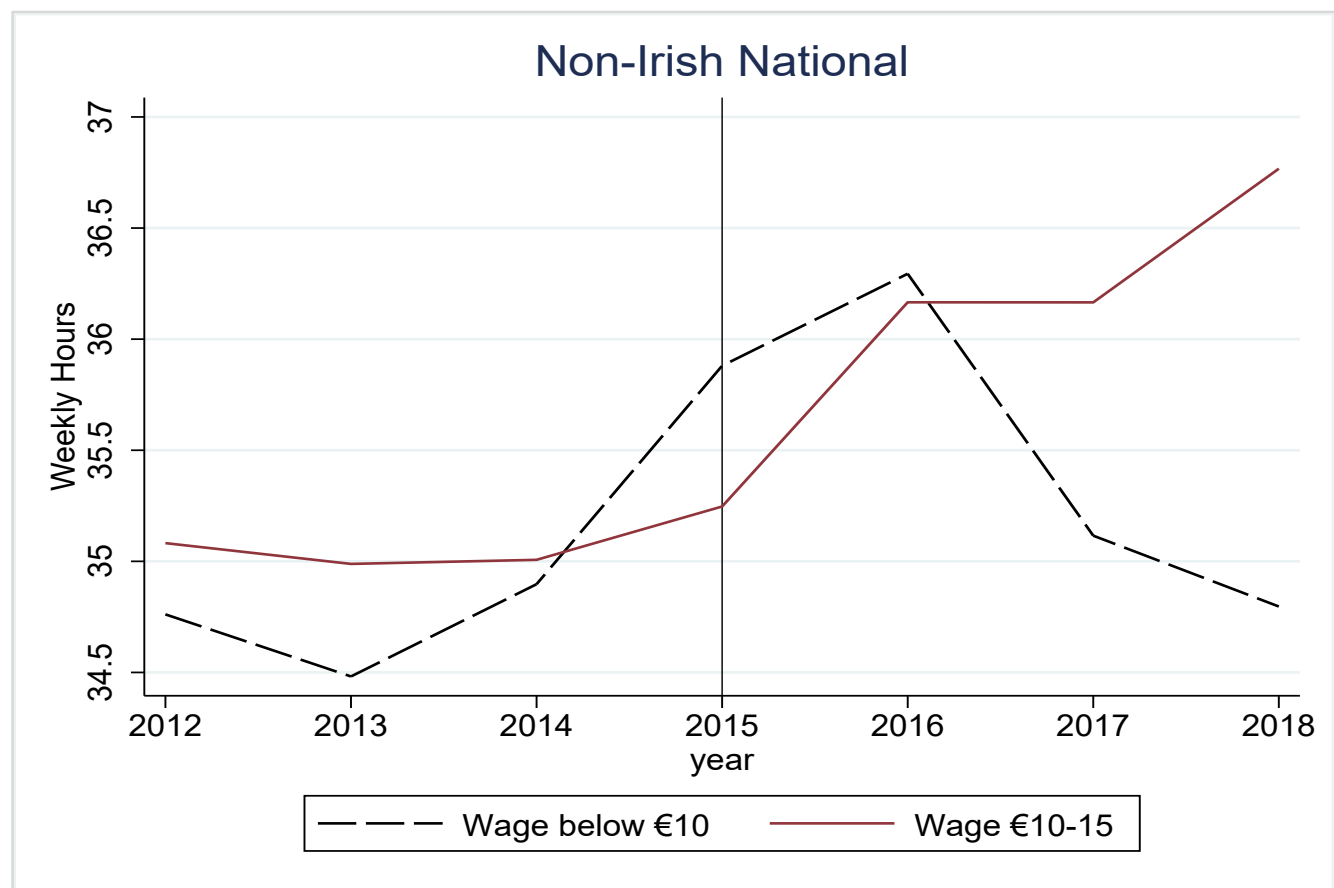

Source: Authors' analysis.

We can represent the changes in hours as elasticities, as this tends to facilitate comparisons with existing studies. For all employees, as well as for the groups that showed a statistically significant effect in 2018 , we represent the estimated decline 
in hours in 2018 as a percentage of the average hours worked before the minimum wage increase (in 2015). ${ }^{22}$ We divide this by 10 per cent, which is the percentage increase in the minimum wage from 2015 to 2018 (€8.65 per hour in 2015 to $€ 9.55$ per hour in 2018). For all minimum wage employees, the elasticity of hours worked with respect to the minimum wage is -0.30 . This closely matches the hours elasticities found by Couch and Wittenburg (2001), Neumark et al. (2004) and McGuinness and Redmond (2019), of $-0.5,-0.3$ and -0.3 respectively.

The calculated elasticity of hours with respect to the minimum wage for the subgroups are higher: industry minimum wage workers (-0.77); accommodation and food minimum wage workers $(-0.83)$; non-Irish nationals on the minimum wage $(-0.69)$.

Previous work by McGuinness et al. (2019) showed that, compared to other sectors, minimum wage workers in the industry sector are more likely to be older, male, married, working full-time and have longer job tenure. As such, they resemble 'career minimum wage workers', as opposed to transient minimum wage workers, such as young people working part-time while also in education, who may work temporarily on minimum wage before progressing to higher pay. This distinction is important as career minimum wage workers may be more at risk from adverse employment effects, given their reliance on full-time, minimum wage work. Our data confirm that minimum wage workers in the industry sector are more likely to resemble career minimum wage workers. While just 14 per cent of minimum wage workers in the industry sector work part-time, the corresponding figure for all other minimum wage workers is 38 per cent. In this paper, we have shown a substantial hours effect for minimum wage workers in the industry sector. Our results are consistent with work by Lordan and Neumark (2018), who find that minimum wage workers in manufacturing industries in the US appear to be particularly susceptible to adverse employment effects following a minimum wage increase. Many workers in these sectors are in jobs that are automatable, such as assembly line workers, and therefore may be relatively easily substituted with machinery or new technology. Therefore, this appears to be a sector that requires careful monitoring and consideration relating to further impacts of future minimum wage changes.

In light of our findings, it is important to note that different possibilities exist that could potentially explain the results. The decline in hours worked could be due to employers reducing hours due to the higher minimum wage. However, it could also be due to the income effect, that is, employees reducing hours in order to consume

22 The average hours worked among all minimum wage workers in 2015 was 32 hours per week. For minimum wage workers in the industry and accommodation and food sectors it was 39 and 31 hours per week, respectively. For non-Irish nationals on the minimum wage, it was 36 hours per week. 
more leisure time in response to a wage rise. However, economic theory generally indicates that income effects are more likely to occur for higher paid workers. Compositional effects may also have a role to play if there is an increase in the percentage of part-time workers. Of course, such a compositional effect could itself be attributed to employer's or employee's actions. In response to a minimum wage rise, employers may replace full-time workers with part-time workers either by altering the hours of existing workers or replacing full-time workers with new parttime workers. Alternatively, more part-time employees may be attracted into the labour market in response to the higher wage. While our administrative data have advantages, fully disentangling such effects is not possible and represents an avenue for future research.

It is also worth noting the potential role of labour-labour substitution. If higher paid workers are more productive than lower paid (minimum wage) workers, then firms may substitute away from the lower paid workers towards higher paid workers in response to a minimum wage increase (Fairris and Bujanda, 2008; Redmond and McGuinness, 2021). The slightly higher-paid control group may be, to a certain extent, substitutes for the treatment group, in which case a reduction in hours among the treatment group would correspond to an increase in hours among the control group. This type of substitutability could amplify the hours reduction experienced by minimum wage workers. If, on the other hand, the treatment group were complements to the control group, this could serve to limit the hours reduction among the treatment group. From Figures 5.1 to 5.4 we can see that, in some cases, the sharp decline in hours worked among the treatment group coincided with continuing increases in the hours worked of the control group, indicating that some labour-labour substitution may be occurring between the two groups.

An additional important consideration is whether, following the minimum wage increases, the average worker was better off, even after taking hours reductions into account. More specifically, were the minimum wage increases from 2016 to 2018 sufficiently large so as to offset any wage loss, for the average worker, due to hours reductions? Again, we carry this analysis out for minimum wage workers in general, as well as for each of the three groups that showed a cumulative hours reduction from 2016 to 2018. In Table 5.3 we show the average weekly wage of minimum wage workers in 2015 , before the minimum wage was increased. This is shown in the first column of results, entitled 'Weekly Wage 2015'. This is calculated as the average hours worked in 2015, for each group, multiplied by the prevailing minimum wage in 2015 , of $€ 8.65$ per hour. We then take the hours reductions into consideration by subtracting the cumulative estimated hours effects from 2016 to 2018 from the 2015 average hours. The adjusted hours are then multiplied by the 2018 minimum wage (€9.55 per hour) and the average weekly wage in 2018 is shown in the second column ('Hours Adjusted Weekly Wage 2018'). If we assume 
that hours would have been unchanged in the absence of a minimum wage increase, we can compare the 2015 weekly wage to the hours adjusted weekly wage in 2018 to see if minimum wage workers are better off, in nominal terms, in 2018 compared to 2015 . Essentially, we are investigating whether the increases in the minimum wage were sufficiently large to offset average hours reductions. The results indicate that all groups, on average, are better off in 2018 despite the hours reductions. For example, for all minimum wage employees, despite the one hour reduction in hours in 2018 compared to 2015, the minimum wage increasing from $€ 8.65$ to $€ 9.55$ per hour was sufficient to see a nominal increase in average weekly wages of $€ 20$, or 7 per cent. The results for industry, accommodation and food and non-Irish nationals are lower, at 2 per cent, 1 per cent and 3 per cent respectively.

It should be noted that the figures in Table 5.3 represent nominal wage changes. The rate of inflation, as measured by the CPI, from December 2015 to December 2018 was 1.1 per cent. Therefore, after taking inflation into account, the average weekly wage of minimum wage workers in accommodation and food is relatively unchanged, while the other groups are still better off. However, it should be noted that the CPI will not fully capture changes to the cost of living. One notable limitation relates to its treatment of housing costs. A recent study by Allen-Coghlan et al. (2020) for Ireland proposes an alternative measure of housing costs, which results in a significantly higher CPI compared to the published CPI results.

TABLE 5.3 ACTUAL 2015 AND ADJUSTED 2018 WEEKLY WAGES

\begin{tabular}{l|c|c|c}
\hline \multicolumn{1}{c|}{ Group } & Weekly Wage 2015 & $\begin{array}{c}\text { Hours Adjusted } \\
\text { Weekly Wage 2018 }\end{array}$ & Difference \\
\hline All MW workers & $€ 277$ & $€ 297$ & $+€ 20(7 \%)$ \\
\hline Industry MW workers & $€ 337$ & $€ 344$ & $+€ 6(2 \%)$ \\
\hline Accommodation and food MW workers & $€ 268$ & $€ 272$ & $+€ 3(1 \%)$ \\
\hline Non-Irish nationals on MW & $€ 311$ & $€ 320$ & $+€ 9(3 \%)$ \\
\hline
\end{tabular}

Source: Authors' analysis.

\subsection{ROBUSTNESS TESTS}

We test the robustness of the results for 2016 and 2017 using alternative criteria to define the treatment group. Note that we are simply testing the robustness of the results for 2016 and 2017. The results for 2018, which ultimately are the estimates of primary interest, are unaffected as we use the 2018 minimum wage as the criteria for treatment assignment in our baseline estimates. ${ }^{23}$

23 They are the estimates of primary interest as they show the cumulative effect of the three rate rises over the period 2016 to 2018. Whatever happened in the intervening years simply forms part of this overall effect. 
Recall that our baseline estimates define the treatment group as anybody earning less than $€ 10.03$ per hour, which is calculated based on the 2018 minimum wage, of $€ 9.55$ per hour, plus 5 per cent. We first test the robustness of the 2016 results when we use the 2016 minimum wage as the treatment assignment criterion. That is, we define the treatment group for 2016 as employees earning less than $€ 9.61$ per hour (€9.15 + 5 per cent). In addition to all minimum wage employees, we carry out these robustness tests for the groups for which we observe significant results: temporary contract workers; industry; accommodation and food; and nonIrish nationals. The results are shown in the first column of Table 5.4, labelled '2016'. For 2016, we do not detect statistically significant results for all minimum wage employees, those in accommodation and food and non-Irish nationals. This is in line with our baseline estimates in Tables 5.1 and 5.2, which also indicate no statistically significant results for these groups in 2016. For minimum wage workers on temporary contracts, we find a reduction of 2.86 hours per week, which is similar to, although slightly larger than, the reduction of 2.45 hours per week detected in Table 5.2. The results for the industry sector are also very similar; -2.74 in Table 5.4 compared to -3.02 in Table 5.2. Therefore, our baseline estimates for 2016 are robust to altering the treatment assignment criterion from workers earning below $€ 10.03$ per hour to workers earning below €9.61 per hour.

TABLE 5.4 ROBUSTNESS TEST ESTIMATES

\begin{tabular}{|l|l|l|}
\hline & 2016 & 2017 \\
\hline All MW Employees & -0.23 & $-0.86^{*}$ \\
\hline Temporary Contract & $(0.49)$ & $(0.45)$ \\
\hline Industry Sector & $-2.86^{*}$ & -1.80 \\
\hline Accommodation and Food & $(1.58)$ & $(1.44)$ \\
\hline Non-Irish Nationals & $-2.74^{* *}$ & -1.27 \\
\hline & $(1.23)$ & $(1.12)$ \\
\hline
\end{tabular}

Source: Authors' analysis.

Next, we test the results for 2017, by defining the treatment group as those earning less than €9.71 per hour (€9.25 + 5 per cent). The results are shown in the second column of Table 5.4, labelled '2017'. For all employees, we detect a statistically significant decline in 2017 of 0.86 hours per week. Our baseline estimate showed a decline of 0.59 hours per week, which was not significant at conventional levels. ${ }^{24}$ Therefore, using the 2017 minimum wage as the defining criteria indicates a slightly larger reduction in hours worked among minimum wage employees in 2017. The magnitude of the estimates for minimum wage workers on temporary contracts, those in the industry sector and those in accommodation and food for 
2017 are in the range of -1 to -2 hours per week, but are not statistically significant, which is in line with the baseline results. The one result that appears different is for non-Irish nationals in 2017. Our baseline estimate in Table 5.2 indicates a statistically significant decline of 2.49 hours per week for this group in 2017 . Our robustness test indicates a decline of -1.69 that is not statistically significant. However, the margin by which this is judged to be not statistically significant is low. The associated $p$-value for the estimate of -1.69 is 0.103 , which is just above the 10 per cent statistical significance level of 0.10 .

We also examine whether our baseline results are sensitive to adjusting the lower threshold for defining the treatment group. Our baseline definition is based on those earning above $€ 6$ per hour and below $€ 10.03$ per hour. We chose $€ 6$ per hour as it approximately equals the lowest legally permitted sub-minimum wage rate that was operational over the time period covered in the analysis. We chose this cut-off to limit the possibility of capturing low-paid employees who are working for non-compliant employers and are therefore being illegally paid a low wage rate. Such employees should not be included in the analysis of minimum wage changes given that their employers may be non-compliant to begin with. However, it may be the case that the $€ 6$ threshold is still too low and potentially includes noncompliant cases. We re-run the analysis based on a higher lower threshold of $€ 7$ per hour. Therefore, the minimum wage group are now defined as individuals earning above $€ 7$ per hour and below $€ 10.03$ per hour.

TABLE 5.5 ROBUSTNESS TEST - VARYING LOWER THRESHOLD OF TREATMENT GROUP

\begin{tabular}{|c|c|c|}
\hline \multicolumn{1}{|c|}{ VARIABLES } & Baseline & $\begin{array}{c}\text { Alternative Treatment } \\
\text { Group (€7 to } € 10.03)\end{array}$ \\
\hline DiD Estimates & & $-1.01^{* *}$ \\
\hline DiD - 2018 & $-0.95^{* *}$ & $(0.46)$ \\
\hline DiD - 2017 & $(0.46)$ & $-0.79 *$ \\
\hline DiD - 2016 & -0.59 & $(0.44)$ \\
\hline & $(0.42)$ & -0.03 \\
\hline Pre-dynamics: $\mathbf{p}$-value & 0.04 & $(0.46)$ \\
\hline Observations & $(0.08)$ & 0.45 \\
\hline
\end{tabular}

Source: Authors' analysis.

Note: $\quad$ Robust standard errors in parentheses. ${ }^{* * *} \mathrm{p}<0.01, * * \mathrm{p}<0.05, * \mathrm{p}<0.1$.

The estimated effects using the alternative criteria, while stronger, are similar to our baseline results. The overall impact of the minimum wage increases over the three-year period is a reduction of 1.01 hours per week among affected workers, compared to an estimated reduction of 0.95 hours per week in our baseline specification. Using the alternative criteria, the estimate for 2017 (following two 
years of increases) is a statistically significant reduction of 0.79 hours per week. In our baseline specification, the estimated effect was -0.59 hours per week, however it was not statistically significant.

Finally, we test whether our baseline result is sensitive to varying the upper threshold for defining the control group. Up to now, the upper threshold for defining the control was fixed at $€ 15$ per hour. We allow this to vary in line with the minimum wage increases. Specifically, the threshold is €15 per hour in 2016 before increasing by 1 per cent, in line with the minimum wage increase, in 2017 to $€ 15.15$ per hour. In 2018 , it increases further by 3 per cent, again in line with the 2018 minimum wage increase, to $€ 15.60$ per hour. Therefore, in this specification we are allowing both the lower cut-off for defining the treatment group to vary (as we did in Table 5.4) as well as allowing the upper cut-off for the control group to vary. The results are shown in Table 5.6. Again, we show them alongside baseline results. The results for 2018 are virtually identical. For 2017, our augmented control group definition indicates a statistically significant reduction of 0.9 hours per week. This compares to our baseline result of -0.59 hours per week which was not statistically significant at conventional levels.

TABLE 5.6 ROBUSTNESS TEST - VARYING UPPER THRESHOLD OF CONTROL GROUP

\begin{tabular}{|c|c|c|}
\hline \multicolumn{1}{|c|}{ VARIABLES } & Baseline & $\begin{array}{c}\text { Alternative Control } \\
\text { Group Definition }\end{array}$ \\
\hline DiD Estimates & & $-0.93^{* *}$ \\
\hline DiD - $\mathbf{2 0 1 8}$ & $-0.95^{* *}$ & $(0.43)$ \\
\hline DiD - $\mathbf{2 0 1 7}$ & $(0.46)$ & $-0.90^{* *}$ \\
\hline DiD - 2016 & -0.59 & $(0.45)$ \\
\hline & $(0.42)$ & -0.23 \\
\hline Pre-dynamics: $\mathbf{p - v a l u e}$ & 0.04 & $(0.49)$ \\
\hline Observations & $(0.08)$ & 0.49 \\
\hline
\end{tabular}

Source: Authors' analysis based on Earnings, Hours and Employment Costs data.

Note: $\quad$ Separate models are estimated for each individual year (2016-2018) for the robustness test results in the second column, according to the varying threshold definition. As the upper threshold changes only apply to 2017 and 2018 , the results for 2016 are identical to those in Table 5.4. The pre-dynamics $p$-value and number of observations in the second column relate to the 2018 specification. Robust standard errors in parentheses. $* * * p<0.01, * * p<0.05, * p<0.1$. 


\section{CHAPTER 6}

\section{Conclusion}

This study uses administrative wage data to analyse the impact of three successive yearly minimum wage increases that took place in Ireland over the period 2016 to 2018. We examine the impact of these minimum wage increases on weekly hours worked of minimum wage employees. The study allows for the assessment of the cumulative impact of three minimum wage increases that might be missed in frameworks that examine the policy effect for one particular year. In addition to examining the effects on minimum wage workers generally, we examine heterogeneous effects for minimum wage workers in different sectors, regions, with different contract types, and of different nationality.

In assessing impacts across all minimum workers, while no immediate impact was observed following the 2016 rate rise, there was a cumulative impact, resulting in a decline of 0.9 hours per week among minimum wage employees following the three rate rises from 2016 to 2018. With respect to the other heterogeneous impacts, we found evidence of declines in weekly hours worked over the 2016 to 2018 period among employees in both the industry and accommodation and food sectors. Minimum wage workers in 2018 in the industry sector were working three hours less per week, while those in the accommodation and food sector were working 2.5 hours less per week. We also found that by 2018, non-Irish minimum wage workers were working three hours less per week than their higher paid, nonIrish counterparts. This reflects the fact that many non-Irish minimum wage workers are located in the sectors that were most affected by the rate rises, namely industry and accommodation and food.

From a policy perspective, the observed declines in hours worked among minimum wage workers in the industry sector may be a particular cause for concern. Previous research has shown that minimum wage workers in the industry sector are more likely to resemble 'career minimum wage employees'. Compared to higher educated, young workers who eventually transition to higher paid jobs, career minimum wage employees may be more dependent on their employment to meet financial commitments and may have lower capacity to absorb any decline in weekly earnings. Nevertheless, we show that the increase in the minimum wage was sufficiently high to offset the hours decline for both real and nominal weekly wages. This was also true for minimum wage workers generally as well as for non-Irish nationals on the minimum wage. While those in the accommodation and food sector, on average, saw a slight nominal increase in weekly wages despite the hours reduction, in real terms their weekly wages were relatively unchanged. 



\section{REFERENCES}

Allegretto, S.A., A. Dube and M. Reich (2011). 'Do Minimum Wages Really Reduce Teen Employment? Accounting for Heterogeneity and Selectivity in State Panel Data', Industrial Relations: A Journal of Economy and Society, Vol. 50 (2), pp. 205-240.

Allegretto, S., A. Dube, M. Reich and B. Zipperer (2017). 'Credible Research Designs for Minimum Wage Studies: A Response to Neumark, Salas, and Wascher', ILR Review, Vol. 70 (3), pp. 559-592.

Allen-Coghlan, M., C. Coffey, M. Martinez-Cillero, I. Kostarakos, K. McQuinn and C. O'Toole (2020). 'Estimating the Cost of Irish Housing for the CPI: A Rental Equivalence Approach', ESRI Working Paper No. 676. Dublin: Economic and Social Research Institute.

Azar, J., E. Huet-Vaughn, I. Marinescu, B. Taska and T. von Wachter (2019). 'Minimum Wage Employment Effects and Labor Market Concentration', NBER Working Paper 26101.

Belman, D. and P. Wolfson (2014). What Does the Minimum Wage Do?. Kalamazoo, MI: W.E. Upjohn Institute for Employment Research.

Booth, A.L., M. Francesconi and J. Frank (2002). 'Temporary Jobs: Stepping Stones or Dead Ends?', Economic Journal, Vol. 112, pp. F189-213.

Brown, C. (1999). 'Minimum Wages, Employment and the Distribution of Income', in O. Ashenfelter and D. Card (eds.), Handbook of Labor Economics, Vol. 3, Amsterdam: North Holland.

Caliendo, M., A. Fedorets, M. Preuss, C. Schröder and L. Wittbrodt (2017). 'The ShortTerm Distributional Effects of the German Minimum Wage Reform', IZA Discussion Paper No.11246, Bonn: IZA.

Caliendo, M., L. Wittbrodt and C. Schröder (2019). 'The Causal Effects of the Minimum Wage Introduction in Germany - An Overview', German Economic Review, Vol. 20 (3), pp. 257-292.

Couch, K.A. and D.C. Wittenburg (2001). 'The response of hours of work to increases in the minimum wage', Southern Economic Journal, Vol. 68, pp. 171-7.

Dickens, R., R. Riley and D. Wilkinson (2015). 'A Re-examination of the Impact of the UK National Minimum Wage on Employment', Economica, Vol. 82 (328), pp. 841-864.

Doucouliagos, H. and T.D. Stanley (2009). 'Publication Selection Bias in Minimum-Wage Research? A Meta-Regression Analysis', British Journal of Industrial Relations, Vol. 47 (2), pp. 406-428.

Dube, A. (2019). Impacts of Minimum Wages: Review of the International Evidence. London: Department of Business, Energy and Industrial Strategy.

Engellandt, A. and R.T. Riphahn (2005). 'Temporary contracts and employee effort', Labour Economics, Vol. 12, pp. 281-99. 
Fairris, D. and L.F. Bujanda (2008). 'The dissipation of minimum wage gains for workers through labor-labor substitution: Evidence from the Los Angeles living wage ordinance', Southern Economic Journal, Vol. 75, No. 2, pp. 473-496.

Harasztosi, P. and A. Lindner (2019). 'Who Pays for the Minimum Wage?', American Economic Review, 109 (8), pp. 2693-2727.

Lordan, G. and D. Neumark (2018). 'People Versus Machines: The Impact of Minimum Wages on Automatable Jobs', Labour Economics, Vol. 52, pp. 40-53.

McGuinness, S. and P. Redmond (2019). 'The Impact of a Minimum-Wage Increase on Temporary-Contract Workers', Fiscal Studies, Vol. 40 (2), pp. 149-173.

McGuinness, S., P. Redmond and J. Delaney (2019). The Prevalence and Effect on Hours Worked of the Minimum Wage in Ireland: A Sectoral and Regional Analysis, ESRI Research Series Number 93. Dublin: ESRI.

Metcalf, D. (2008). 'Why has the British national minimum wage had little or no impact on employment?', Journal of Industrial Relations, Vol. 50, pp. 489-512.

Mora, R. and I. Reggio (2015). 'didq: A Command for Treatment-Effect Estimation under Alternative Assumptions', The Stata Journal, Vol. 15 (3), pp. 796-808.

Neumark, D. and P. Shirley (2021). 'Myth or Measurement: What does the New Minimum Wage Research Say about Minimum Wages and Job Loss in the United States', NBER Working Paper 28388.

Neumark, D. and W. Wascher (2017). 'Reply to "credible research designs for minimum wage studies"', ILR Review, Vol. 70 (3), pp. 593-609.

Neumark, D., M. Schweitzer and W. Wascher (2004). 'Minimum wage effects throughout the wage distribution', Journal of Human Resources, Vol. 39, pp. 425-50.

Neumark, D., J.I. Salas and W. Wascher (2014). 'Revisiting the Minimum Wage Employment Debate: Throwing out the Baby with the Bathwater?', ILR Review, 67 (3), pp. 608-648.

Okudaira, H., M. Takizawa and K. Yamanouchi (2019). 'Minimum Wage Effects Across Heterogeneous Markets', Labour Economics, Vol. 59, pp. 110-122.

Pusch, T. and M. Rehm (2017). 'Positive Effekte des Mindestlohns auf Arbeitsplatzqualitat und Arbeitszufriedenheit', Wirtschaftsdienst, Vol. 97, pp. 409-414.

Redmond, P., B. Maître, S. McGuinness and K. Maragkou (2021). A Comparative Assessment of Minimum Wage Employment in Europe, ESRI Research Series Number 123. Dublin: ESRI.

Stewart, M. (2004). 'The Employment Effects of the National Minimum Wage', The Economic Journal, Vol. 114 (494), pp. C110-C116.

Stewart, M.B. (2012). 'Wage Inequality, Minimum Wage Effects, and Spillovers', Oxford Economic Papers, Vol. 64, pp. 616-34.

Stewart, M.B. and J.K. Swaffield (2008). 'The Other Margin: Do Minimum Wages Cause Working Hours Adjustments for Low-wage Workers?', Economica, Vol. 75, pp. 148-67. 
Vom Berge, P. and H. Frings (2020). 'High-Impact Minimum Wages and Heterogeneous Regions', Empirical Economics, Vol. 59 (2), pp. 701-729.

Wolfson, P. and D. Belman (2019). '15 Years of Research on US Employment and the Minimum Wage', Labour, Vol. 33 (4), pp. 488-506. 
Whitaker Square,

Sir John Rogerson's Quay, Dublin 2

Telephone +35318632000

Email admin@esri.ie

Web www.esri.ie

Twitter @ESRIDublin 